\title{
TINGKAT KEPATUHAN PASIEN TENTANG PENGGUNAAN ANTIBIOTIKA (AMOXICILLIN DAN AMPISILIN) DI PUSKESMAS TAMALANREA JAYA KOTA MAKASSAR
}

\author{
*)Murniati \\ *)Akademi Farmasi Sandi Karsa Makassar \\ *)Program Studi D-III Farmasi Sandi Karsa Makassar
}

\begin{abstract}
ABSTRAK
Penggunaan antibiotika (amoxicillin dan ampisilin) di Indonesia jauh lebih banyak dan mencemaskan karena penggunaan dosis dan waktu terapi yang tidak sesuai yang dapat menimbulkan masalah meningkatnya resistensi terhadap penggunaan antibiotika (amoxicillin danampisilin), kepatuhan pasien terhadap penggunaan antibiotika (amoxicillin dan ampisilin) sangat mempengaruhi terjadinya resistensi. Penelitian ini bertujuan untuk mengetahui tingkat kepatuhan pasien tentang penggunaan antibiotika (amoxicillin dan ampisilin) di Puskesmas Tamalanrea Jaya Kota Makassar.Penelitian ini adalah penelitian deskriptif, yaitu menggambarkan persentase mengenai tingkat kepatuhan pasien tentang penggunaan antibiotika (amoxicillin dan ampisilin) di Puskesmas Tamalanrea Jaya Kota Makassar. Hasil penelitian yang didapatkan, dari jumlah responden sebanyak 78 orang yang patuh sebanyak 88,66\% dan yang tidak patuh sebanyak 13,33\%. Kesimpulan dari penelitian ini didapatkan Tingkat Kepatuhan Pasien Tentang Penggunaan Antibiotika (amoxicillin dan ampisilin) Di Puskesmas Tamalanrea Jaya Kota Makassar masuk dalam kategori patuh. Saran bagi Puskesmas Tamalanrea Jaya Kota Makassar agar pelayanan dalam pemberian informasi obat dipertahankan dan ditingkatkan lagi.
\end{abstract}

Kata Kunci : Pasien, Kepatuhan, Antibiotika, Puskesmas.

\section{PENDAHULUAN}

\section{A. Latar Belakang}

Di jaman modern seperti pada saat ini begitu banyak penyakit yang kita jumpai, mulai dari penyakit-penyakit yang ringan hingga penyakit yang dapat menyebabkan kematian.Hal ini bisa timbul karena berbagai faktor penyebab, baik dari diri kita sendiri, lingkungan atau faktor keturunan.Karena banyaknya penyakit tersebut maka semakin banySak pula obat-obatan yang kita jumpai, baik itu untuk suplemen, mencegah atau untuk mengobati.

Antibiotika, yang pertama kali ditemukan oleh Paul Ehlrich pada 1910, sampai saat ini masih menjadi obat andalan dalam penanganan kasus-kasus penyakit infeksi. Pemakaiannya selama 5 dekade terakhir mengalami peningkatan yang luar biasa, hal ini tidak hanya terjadi di Indonesia tetapi juga menjadi masalah di negara maju seperti Amerika Serikat. The Center for Disease Control and Prevention in USA menyebutkan terdapat 50 juta peresepan antibiotik yang tidak diperlukan (unnescecery prescribing) dari 150 juta peresepan setiap tahun (Akalin,2002).

Antibiotika merupakan senyawa atau kelompok obat yang dapat mencegah perkembangbiakan berbagai bakteri dan mikroorganisme berbahaya dalam tubuh.Selain itu, antibiotika juga digunakan untuk menyembuhkan penyakit menular yang disebabkan oleh protozoa dan jamur.Meski sering masuk ke dalam resep, mulai sekarang gunakan antibiotik dengan lebih bijak. Antibiotika menyembuhkan penyakit dengan membunuh atau melemahkan bakteri.Dan hingga hari ini lebih dari 100 antibiotika tersedia untuk menyesmbuhkan penyakit ringan hingga yang membahayakan kelangsungan hidup.Meskipun antibiotika berguna untuk menyembuhkan infeksi bakteri, tetapi jangan lupakan efek sampingnya (Deshpande et al, 2011).

Tetapi belum banyak orang yang mengetahui bahwa jika mengonsumsi antibiotika yang tidak tepat dapat menyebabkan resistensi dan mengancam nyawa.Ketika seseorang resisten terhadap antibiotika, ada beberapa penyakit dan Resistensi antibiotika terhadap mikroba menimbulkan beberapa konsekuensi yang fatal.Penyakit infeksi yang disebabkan oleh bakteri yang gagal berespon terhadap pengobatan mengakibatkan perpanjangan penyakit, meningkatnya resiko kematian dan semakin lamanya masa rawat inap di rumah sakit.Ketika respon terhadap pengobatan menjadi lambat bahkan gagal, pasien menjadi infeksius untuk beberapa waktu yang lama. Hal ini memberikan peluang yang lebih besar bagi galur resisten untuk menyebar kepada orang lain. Kemudahan transportasi dan 
globalisasi sangat memudahkan penyebaran bakteri resisten antar daerah, negara, bahkan lintas benua. Semua hal tersebut pada akhirnya meningkatkan jumlah orang yang terinfeksi dalam komunitas (Deshpande et al, 2011).

Salah satu obat yang digunakan dokter dalam pengobatan terhadap pasien adalah antibiotika, karena efektif dalam pengobatan infeksi dan kemampuan obat tersebut menghambat serta membunuh mikroorganisme.Hal ini berarti dalam pengobatan modern, antibiotika tetap memiliki peranan penting utamanya melindungi dan memulihkan kesehatan masyarakat dari serangan penyakit infeksi.

Antibiotika bertujuan untuk mencegah dan mengobati penyakit-penyakit infeksi.Pemberian pada kondisi yang bukan disebabkan oleh infeksi banyak ditemukan dalam praktek sehari-hari, baik di Pusat Kesehatan Masyarakat (Puskesmas), Rumah Sakit maupun praktek swasta. Proses pemilihan yang biasa dilakukan secara konsisten mengikuti standar baku akan menghasilkan penggunaan obat sesuai dengan kriteria kerasionalannya.

Berdasarkan tingkat pengetahuan masyarakat serta fakta yang ditemui sehari-hari, tampaknya penggunaan antibiotika di Indonesia jauh lebih banyak dan mencemaskan karena penggunaan dosis dan waktu terapi yang tidak sesuai yang dapat menimbulkan masalah meningkatnya resistensi terhadap penggunaan antibiotika.

Resisten sel mikroba ialah suatu sifat tidak terganggunya atau kebalnya kehidupan sel mikroba oleh antimokroba, hal ini dapat ditimbulkan oleh beberapa faktor salah satunya ialah tidak tepatnya waktu terapi.Kepatuhan pasien terhadap penggunaan antibiotika sangat mempengaruhi terjadinya resistensi.

Menurut beberapa penelitian sebelumnya mengenai tingkat kepatuhan terhadap penggunaan obat bahwa, perilaku atau ketaatan pasien mengenai penggunaan obat-obatan masih sangat rendah yang disebabkan beberapa faktor, di antaranya; karena kurangnya pengetahuan tentang penggunaan obat, minimnya pendidikan pasien, dan beberapa faktor lain baik dari luar ataupun dari dalam diri pasien itu sendiri.

Menurut hasil penelitian Rahmadi yang dilakukan di Rumah Sakit Dr. Cipto Mangunkusumo Jakarta tentang "Kepatuhan Berobat dengan Antibiotika jangka pendek" mendapatkan hanya $75 \%$ pasien yang patuh terhadap penggunaan antibiotika dan sisanya $25 \%$ tidak patuh( Rahmadi, 2008).

Puskesmas Tamalanrea Jaya adalah salah satu Puskesmas yang berkedudukan di kota Makassar, setelah melakukan observasi awal di
Puskesmas ini dengan cara mengambil beberapa sampel (pasien) dan memberi beberapa pertanyaan, maka ditemukan $40 \%$ dari 10 pasien yang sebelumnya pernah mengkonsumsi antibiotika tidak menghabiskan obat antibiotika yang diberikan oleh dokter (Mei, 2013).

Melihat banyaknya dampak buruk dari penggunaan antibiotika yang tidak tepat maka perlu kiranya perhatian yang cukup terhadap masalah ini, dan perlu dilakukan penelitian tentang seberapa besar tingkat kepatuhan pasien terhadap penggunaan antibiotika di Puskesmas Tamalanrea Jaya.

\section{B. Rumusan Masalah}

Berdasarkan latar belakang di atas maka dapat dirumuskan masalahnya adalah bagaimana tingkat kepatuhan pasien tentang penggunaan antibiotika (amoxicillin dan ampisilin) di Puskesmas Tamalanrea Jaya.

\section{Tujuan Penelitian}

Tujuan penelitian ini adalah untuk mengetahui tingkat kepatuhan pasien tentang penggunaan antibiotika (amoxicillin dan ampisilin) di Puskesmas Tamalanrea Jaya.

\section{Manfaat Penelitian}

Penelitian ini diharapkan mampu mempresentasekan informasi tentang kepatuhan pasien terhadap penggunaan antibiotika (amoxicillin dan ampisilin) di Puskesmas Tamalanrea Jaya. Hasil penelitian ini diharapkan bisa menjadi masukan dalam bentuk informasi yang bermanfaat bagi Puskesmas Tamalanrea Jaya untuk mengetahui seberapa besar tingkat kepatuhan pasien tentang penggunaan antibiotika (amoxicillin dan ampisilin) di Puskesmas Tamalanrea Jaya.

\section{METODE PENELITIAN}

\section{A. Jenis Penelitian}

Penelitian ini adalah penelitian deskriptif, yaitu menggambarkan persentase mengenai tingkat kepatuhan pasien tentang penggunaan antibiotika di Puskesmas Tamalanrea Jaya Makassar dengan cara membagikan kuesioner kapada pasien setelah mengkonsumsi antibiotika.

\section{B. Waktu Dan Tempat Penelitian}

Penelitian ini telah dilakukan di Puskesmas Tamalanrea Jaya Kecamatan Tamalanrea Kota Makassar pada bulan Maret 2020.

\section{Populasi dan Sampel}

1. Populasi

Populasi dalam penelitian ini adalah pasien yang datang berobat di Puskesmas 
Tamalanrea Jaya dan mengkonsumsi antibiotika (amoxicillin dan ampisilin) serta berdomisili di wilayah kerja Puskesmas Tamalanrea Jaya.

2. Sampel

Cara pengambilan sampel pada penelitian ini menggunakan teknik non-random sampling (pengambilan secara tidak acak), Sampel dalam penelitian ini adalah pasien yang mendapatkan antibiotika(amoxicillin dan ampisilin).

Adapun besar sampel ditentukan dengan rumus besar sampel menurut Slovin berikut :

$$
\mathrm{n}=\frac{N}{N \cdot a^{2}+1}
$$

Keterangan :

$\mathrm{n}=$ Jumlah sampel penelitian

$\mathrm{N}=$ Jumlah populasi

$\mathrm{d}=$ Presisi (ditetapkan 10\% dengan tingkat kepercayaan 95\%).

Diketahui $\mathrm{N}=350$

$$
\begin{aligned}
& n=\frac{350}{1+350(0,1)^{2}} \\
& n=\frac{350}{1+3,5} \\
& n=\frac{350}{4,5} \\
& =77,77(78) \text { orang }
\end{aligned}
$$

Sehingga sampel di tetapkan sebanyak 78 orang.

\section{Kriteria sampel}

Sampel pada penelitian ini adalah pasien yang 3 kali datang berobat di Puskesmas Tamalanrea Jaya dengan kriteria sampel; pasien yang mendapatkan antibiotika yang berusia 17 tahun keatas dan bersedia untuk mengisi kuisioner.

\section{Teknik Pengumpulan Dan Pengelolahan Data}

1. Pengumpulan data

Teknik pengumpulan data yang digunakan dalam proses penelitian ini adalah dengan pasien yang telah berobat di Puskesmas Tamalanrea Jaya lalu membagikan kuesioner. Data yang diperoleh dengan mengumpulkan hasil jawaban dari kuesioner tersebut diskoring, dipresentasekan dan dibuat dalam bentuk tabel dan grafik batang.

2. Pengolahan data

Tekhnik pengolahan data berdasarkan cara pengukuran dengan skala Guttman:
Skor jawaban positif $=1$

Skor jawaban negatif $=0$

Presentase Skor $=\frac{\text { [umlah skor }}{\text { Skor ideal }} \times 100 \%$

Skor Ideal = Jumlah Responden $\quad X \quad 1 \quad X \quad$ Jumlah Pertanyaan

Nilai yang didapat dari masing-masing responden kemudian dipresentasekan berdasarkan kriteria jawaban yang benar:

$>50 \%=$ Patuh

$>\leq 50 \%=$ Tidak patuh

Skor Ideal $=$ Jumlah Responden $\mathrm{X}$ Skor Tertinggi $\mathrm{X}$ Jumlah Pertanyaan

\section{E. Defenisi Operasional}

Tingkat kepatuhan dalam penelitian ini adalah keteraturan pasien dalam mengkonsumsi antibiotika sesuai dengan aturan pakai, waktu paruh dan hari sesuai dengan Resep.

\section{HASIL DAN PEMBAHASAN}

\section{A. Hasil Penelitian}

Berdasarkan penelitian yang dilakukan terhadap 78 orang responden atau pasien yang mengkunsumsi antibiotika pada bulan Juni di Puskesmas Tamalanrea Jaya Kota Makassar. Hasil yang diperoleh selama penelitian berdasarkan item pertanyaan sebagai berikut:

1. Karakteristik Responden

a. Distribusi karakteristik responden menurut jenis kelamin

Tabel I. Distribusi karakteristik responden menurut jenis kelamin

\begin{tabular}{ccc}
\hline Jenis Kelamin & Frekuensi (f) & Presentase (\%) \\
\hline Laki-laki & 21 & $26,92 \%$ \\
\hline Perempuan & 57 & $73,08 \%$ \\
\hline Total & 78 & 100 \\
\hline
\end{tabular}

Berdasarkan tabel I data karakteristik responden menurut jenis kelamin menunjukkan bahwa dari 78 responden, responden yang berjenis kelamin laki - laki sebanyak 21 (26,92\%) responden, dan yang berjenis kelamin perempuan sebanyak $57 \quad(73,08 \%)$ responden.

b. Distribusi responden menurut jenis pendidikan

Table II. Distribusi responden menurut jenis pendidikan 


\begin{tabular}{ccc}
\hline Pendidikan & Frekuensi (f) & Presentase (\%) \\
\hline Tidak Sekolah & 3 & $3,85 \%$ \\
\hline SD & 21 & $26,92 \%$ \\
\hline SLTP & 15 & $19,23 \%$ \\
\hline SMA & 23 & $29,49 \%$ \\
\hline D3 & 9 & $11,54 \%$ \\
\hline S1 & 7 & $8,97 \%$ \\
\hline Total & 78 & 100 \\
\hline
\end{tabular}

Berdasarkan tabel II data karakteristik responden menurut jenis pendidikan menunjukkan bahwa dari 78 responden, terdapat $3(3,85 \%)$ responden yang tidak berpendidikan, $21(26,92 \%)$ responden yang pendidikan terakhirnya sampai Sekolah Dasar, $15(19,23 \%)$ responden yang hanya sampai Sekolah Lanjut Tingkat Pertama, 23 $(29,49 \%)$ responden yang sampai Sekolah Menengah Atas, 9 (11,54\%) responden yang sampai D3 dan $7(8,97 \%)$ responden yang sarjana.

2. Variable Yang Diteliti

a. Frekuensi Responden terhadap kepatuhan ketepatan penggunaan obat antibiotik.

Tabel III. Frekuensi Responden terhadap kepatuhan ketepatan penggunaan obat antibiotika (amoxicillin dan ampisilin)

\begin{tabular}{ccccccc}
\hline No & $\begin{array}{c}\text { Ketepatan } \\
\text { Penggunaan }\end{array}$ & \multicolumn{2}{c}{ Butir Soal } & \multicolumn{2}{c}{$\begin{array}{c}\text { Hasil } \\
\text { Operasional }\end{array}$} \\
\cline { 3 - 7 } & $\begin{array}{c}\text { Obat } \\
\text { Antibiotika }\end{array}$ & $\mathbf{1}$ & $\mathbf{2}$ & $\mathbf{3}$ & Jumlah & \% \\
\hline $\mathbf{1}$ & Cukup & 65 & 52 & 73 & 190 & 81,19 \\
\hline $\mathbf{2}$ & Kurang & 13 & 26 & 5 & 44 & 18,80 \\
\hline & Total & 78 & 78 & 78 & 234 & 100 \\
\hline
\end{tabular}

Tabel III diatas menunjukkan bahwa jumlah jawaban responden yang menjawab Positif tentang kepatuhan ketepatan penggunaan obat antibiotika sebanyak $190 \div 234$ x $100 \%=81,19 \%$ dan termasuk dalam kategori patuh.

b. Frekuensi Responden terhadap kepatuhan frekuensi penggunaan antibiotika (amoxicillin dan ampisilin)

Tabel IV. Frekuensi Responden tentang kepatuhan frekuensi penggunaan antibiotik (amoxicillin dan ampisilin)

\begin{tabular}{|c|c|c|c|c|c|c|}
\hline \multirow[t]{2}{*}{ No } & \multirow{2}{*}{$\begin{array}{c}\text { Ketepatan } \\
\text { Penggunaan } \\
\text { Obat Antibiotik }\end{array}$} & \multicolumn{3}{|c|}{ Butir soal } & \multicolumn{2}{|c|}{$\begin{array}{c}\text { Hasil } \\
\text { Operasional }\end{array}$} \\
\hline & & 1 & 2 & 3 & Jumlah & $\%$ \\
\hline 1. & Cukup & 76 & 52 & 73 & 202 & 86,33 \\
\hline 2. & Kurang & 13 & 26 & 4 & 32 & 13,67 \\
\hline
\end{tabular}


Secara keseluruhan tingkat kepatuhan pasien dapat dilihat pada tabel berikut:

Tabel VI. Tingkat kepatuhan pasien terhadap penggunaan antibiotika (amoxicillin dan ampisilin) di Puskesmas Tamalanrea Jaya

\begin{tabular}{ccc}
\hline No. & Kategori & Persentase (\%) \\
\hline $\mathbf{1}$ & Patuh & $86,66 \%$ \\
\hline $\mathbf{2}$ & Tidak Patuh & $13,33 \%$ \\
\hline & Jumlah & $\mathbf{1 0 0}$ \\
\hline
\end{tabular}

\section{PENUTUP}

\section{A. Kesimpulan}

Berdasarkan hasil penelitian pengolahan data dan pembahasan yang telah dilakukan, maka dapat disimpulkan bahwa tingkat kepatuhan pasien tentang penggunaan antibiotika (amoxicillin dan ampisilin) di Puskesmas Tamalanrea Jaya Kota Makassar pada Bulan Juni yaitu $86,66 \%$ atau kategori patuh.

B. Saran

Berdasarkan kesimpulan yang ada maka saran bagi Puskesmas Tamalanrea Jaya Makassar khususnya bagian Kamar Obat dalam hal ini farmasis supaya pelayanannya dipertahankan dan ditingkatkan lagi agar kessspatuhan pasien tentang penggunaan antibiotik bisa mencapai $100 \%$.

\section{DAFTAR PUSTAKA}

Alamsyah. 2012. Manajemen Pelayanan Kesehatan. Nuha Medika : Jogjakarta

Akh Akalin, E. H. 2002. The evolution of guidelines in an era of cost containment Surgical prophylaxis J Hosp infect.

Ganiswarna, S.G, 1995, Farmakologi dan terapi, Edisi IV, Bagian farmakologi Fakultas Kedokteran Indonesia, Jakarta.

Kepmenkes No.128 tahun 2004 Tentang Susunan Organisasi Puskesmas

Moleong, Lexy J, 2004. Metodologi Penelitian Kualitatif. Remaja Rosda Karya, Bandung.
Muchid, A, 2006, Pedoman Pelayanan Kefarmasian Di Puskesmas. Jakarta

Pratiwi. T. S., 2008. Mikrobiologi Farmasi. Bandung. PT. Gelora Aksara Pratama.

Rahmadi.W.2008.Kepatuhan Berobat dengan antibiotik Jangka Pendek di Poliklinik Umum Departemen Ilmu Kesehatan anak Rumah Sakit Dr. Cipto Mangunkusumo, Jakarta

Santoso, N. dkk, 2015 "Farmakologi Jilid II", Departemen Kesehatan RI Badan Pengembangan dan Pemberdayaan Sumber Daya Manusia Kesehatan, Jakarta

Sarudji, D. dkk,2015 "Ilmu Kesehatan Masyarakat, Jilid I', Departemen Kesehatan RI Badan Pengembangan dan Pemberdayaan Sumber Daya Manusia Kesehatan, Jakarta

Soekidjo Notoatmodjo. 2005. Metodologi Penelitian Kesehatan. Jakarta : Rineka Cipta

Sugiyono,2010.Metode Penelitian Kuantitatif Kualitatif R\&D. Alfabeta.Bandung.

Sugono.Dendy, 2008.Kamus Besar Bahasa Indonesia Daling. Jakarta

Tim penyusun, 2013 ,Pedoman Penulisan Karya Tulis Ilmiah Akademi Farmasi Sandi Karsa, Makassar

Tjay. H., Rahardjah K., 2008, Obat-obat penting, Khasiat penggunaan dan Efek-efek sampingnya, edisi VI, Dirjen POM, DEPKES RI, Jakarta.

Trihono, 2005. Manajemen Puskesmas Berbasis Paradigma Sehat. Cv. Sagung Seto, Jakarta.

Widyanti K. Hubungan antara jumlah dukungan sosial yang diterima dengan kepatuhan menjalani terapi ARV pada Odha. Tesis FPSI UI, 2008. 